\title{
Egalitarian and utilitarian approaches in the green logistics of multimodal grain's transportation
}

\author{
Viktor Bogachev, Alexandra Kravets, and Olga Mulenko* \\ Rostov State Transport University (RSTU), 344038, 2, Rostovskogo Strelkovogo Polka Narodnogo \\ Opolcheniya sq., Rostov-on-Don, Russian Federation
}

\begin{abstract}
A multi-agent approach is proposed in the complex researches time and cost indicators of multimodal freight transportation on the railway loop, carried out in the direction of the port unloading stations. Along with the traditional subjects of the transportation process, such as the infrastructure owner, the carrier, the operator company (the rolling stock owner), the logistics company and clients (consignors and cargo's owners), a "green logistics" agent is introduced. This agent is a concept that accumulates forms of manifestation of a conscious attitude of society to the environment in transport and logistics activities. Based on the assessment of the transport and technological railway loop infrastructure and the cost of transport services, a mathematical model of the freight transportation process is built, which is a multi-criteria transport problem. The choice of objective functions and constraints in the task is aimed at, first of all, taking into account the diverse interests of the agent "green logistics". The algorithm for solving the problem, presented in the form of an integer programming problem, is based on the fundamental principles of the egalitarian and utilitarian approaches in the welfare theory. The implementation of the corresponding calculations for the grain transportation is performed in the environment of the computer mathematics system.
\end{abstract}

\section{Introduction}

Briefly, "green logistics" can be presented as a synthetic scientific direction, the purpose of the research in which is the development of innovative logistics technologies that minimize harmful emissions and the resulting pollution into the environment at all supply chain stages.

Modern research is devoted to various "green logistics" aspects. So, in [1], the connection of "green logistics" with the economic, environmental and social spheres of society is investigated. "Green" supply chain management methods are discussed in [2-5]. The "green logistics" concept in relation to various modes of transport is presented in [6-8].

Transport is one of the main environmental pollutants. The share of harmful substances emissions into the atmosphere from stationary and mobile sources associated with transport

\footnotetext{
*Corresponding author: mikasya@yandex.ru
} 
is higher than in other industries. The most common air pollutants from mobile sources are carbon monoxide, nitrogen oxides and volatile organic compounds [9].

Pollution resulting from the transportation process at all logistics chain stages is expressed not only by the emission of harmful substances from vehicles, but also by the release of heat from boiler houses, noise and vibration pollution, ineffective waste disposal, pollution of water resources (for example, when washing rolling stock) and others. At the same time, some parameters characterizing the pollution degree are permanent (stationary sources), others are variable (those that depend on the volume of cargo, the number of trains, the number of shunting operations, etc.).

Leading integrator companies are already practicing the introduction of "green" technologies in logistics. Here are some of them.

Federal Express (USA) introduces delivery vehicles hydrogen fuel cell that have $166 \%$ more range than hydrocarbon fuels.

VR Group (Finnish Railways) is planning to electrify railways as much as possible (for passenger traffic, this has already been done by $94 \%$ ).

Deutsche Bahn Schenker Rail has developed over 150 relevant measures that cover five areas: climate protection, nature conservation, resource protection, noise reduction and social responsibility [10].

DHL is improving logistics, making it more sustainable and environmentally friendly through the implementation of various green logistics programs [11]. Among them are crossdocking, the use of innovative transport technologies, the transition to alternative fuels, optimization of the route network in order to reduce greenhouse gas emissions, as well as the use of containers and packaging that are safe for the environment (consisting boxes of $100 \%$ degradable material).

This paper examines the possibilities and results of the innovative logistics technology's introduction to reduce the railway transport impact on the environment. As an object of research, the North-Caucasian Railway loop was selected, within which the loading and unloading of grain cargo large volumes is carried out, including those for export to the AzovBlack Sea basin ports. It is difficult to overestimate the economic feasibility of the specified exports range (both for the exporter and for the importers). The technologies development that makes it possible to transport grain cargo with the lowest transport component in price and at the same time, taking into account the green logistics principles, is directly related to the food and environmental safety of Russia and importing countries.

In order to take into account, the various participants interest in the transportation process, the authors turn to two main approaches in the welfare theory [12]. At the same time, a number of indicators and restrictions are introduced in the optimization problem, which allow not only to assess the efficiency of transportation from the point of view of its economic feasibility, but also to reduce the environmental impact of railway transport.

\section{Methods}

In general, methodological terms we turn to egalitarian and utilitarian approaches in the welfare theory in the sense that it is stated in [12].

The aim of researches is a construction of mathematical complex model of railway transportation process in the railway network part, carried out in the multimodal transport and technological system.

Objective functions and restrictions in multi-criteria optimization of transport type problem are selected in such a way that the economic, organizational and other interests of the participants in the transportation process under consideration are taken into account in one form or another (following the terminology [12], name them "agents"), as well as the interests of green logistics in the region under consideration. 
When setting and solving the optimization problem, we proceed from the fact that a balance of agent's interests must be observed in accordance with the operational situation at the considered of the railway network part.

In transport and logistics term, the optimization algorithm which proposed in the paper is more complex and more informative than in $[13,14]$. This applies both to the set of objective functions and constraints, as well as to the forms of implementation of egalitarian and utilitarian approaches in optimizing the freight transportation process. Let us start with the statement of the general structure of the model under consideration.

\subsection{Mathematical model of the freight transportation process}

In this paper, an approach to freight transportation mathematical modeling, which leads to the formulation and solution of a transport problem, has been developed. $m$ loading stations and $n$ unloading stations are considered. Let us $a_{i}$ be a number of forwarder routes with some cargo, scheduled for export from the $i$ loading station $(i=1,2, \ldots, m)$, and $x_{i j}$ be a quantity of forwarder routes, which may proceed from the $i$ loading station to address of the $j$ unloading station $(j=1,2, \ldots, n)$. For a multitude $D$ of feasible transportation plans $\left(x_{i j}\right)$ it is assumed that the equalities are fulfilled:

$$
\sum_{j=1}^{n} x_{i j}=a_{i}(i=1,2, \ldots, m)
$$

The equations (1) express the assumption that all grain planned for export, located at the loading stations under consideration, should be exported.

As for initial openness of transport problem in term of unloading stations, in the process of adapting the model to specific transport and logistic activities in the considered railway network part, a number of additional restrictions will be imposed on the multitude $D$.

At the same time, an attempt is made to take into account both the multimodal nature of transportation and (in a very significant way) the "green" specificity of the situation under consideration.

The indicators of the transportation process introduced further make it possible to take into account its expediency, organizational level and, as already noted, the green logistics interests.

Let us start with a classical cost indicator expressed by objective function of the form:

$$
c=\sum_{i=1}^{m} \sum_{j=1}^{n} c_{i j} x_{i j}
$$

Here $c_{i j}$ is the cost of transportation of one forwarder route on the section between $i$ loading station $(i=1,2, \ldots, m)$ and $j$ unloading station $(j=1,2, \ldots, n)$.

Following the integrated approach in the researching of the freight transportation proposed in $[13,14]$ we will also consider the following time indicators.

Let $t_{i j}$ be an average time on the route in the section between $i$ loading station $(i=1,2, \ldots, m)$ and $j$ unloading station $(j=1,2, \ldots, n)$.

We introduce a set of indicators expressed by objective functions of the form:

$$
\tau^{(j)}=\sum_{i=1}^{m} t_{i j} x_{i j} \quad(j=1, \ldots, n),
$$

Each of the indicators $\tau^{(j)}$ is called the sum of all time of the transportation plan $\left(x_{i j}\right)$ in the direction of the corresponding (that is $j$ ) unloading station.

We will also consider the "global" (within the framework of the transport and logistics structure under consideration) time characteristic of the transportation process, which is expressed by an objective function of the form: 


$$
T=\sum_{i=1}^{m} \sum_{j=1}^{n} t_{i j} x_{i j}
$$

The indicator $T$ will be called sum of all time of the transportation plan $\left(x_{i j}\right)$. This indicator expresses the sum of all time spent at the railway network part of all forwarder routes that participate in the implementation of the transportation plan $\left(x_{i j}\right)$.

\subsection{About the agents under consideration and transportation indicators}

As agents, we will consider the infrastructure owner, the carrier, the operator company (the rolling stock owner), logistics company and clients (consignors, cargo's owners). In addition to the traditional subjects of the transportation process, we are accentuating the positioning of another agent, which we will refer to as "green logistics". The specified agent is in a sense a collective image. "Green logistics" is a concept that accumulates various forms of manifestation of the conscious attitude of society to the environment in relation to transport and logistics activities. By rational schemes of cargo flows distribution, we will understand those in which the interests of all the agents in question are taken into account in one form or another and to some extent.

The indicator $c$ expresses the cost of transportation of all forwarder routes that participate in the implementation of the transportation plan $\left(x_{i j}\right)$.

This characteristic of the transportation process allows for different approaches and interpretations from the point of view of the interests of various participants in this process. By the means of indicator $c$, not only the economic parameters of transportation are taken into account.

Namely, the transport component in the cost of transported goods, the customer's costs and (as a result) the competitiveness of the type of transport used. The value $c$ also indicates the level of optimal use of resources. We are talking about resource-saving technologies used by the carrier, companies operating traction and non-traction rolling stock, as well as the infrastructure owner.

Indicators $\tau^{(j)}(j=1, \ldots, n)$ express the time spent at the railway network part of all those forwarder routes from this transportation plan $\left(x_{i j}\right)$, which turn out to be directed to $j$ unloading stations.

These indicators make it possible to identify unloading stations that are of particular interest in the ongoing researches from the point of view of the causes and consequences of the congestion of the relevant railway network parts. Note that the indicators $\tau^{(j)}$ are quite objective estimates of the railway network parts congestion degree. Thus, it becomes possible to monitor and regulate compliance with the green logistics principles in the considered transportation process. In particular, the interests of the agent "green logistics" are taken into account in relation to the directions towards the Black Sea coast of the Caucasus, traditionally belonging to the resort.

If we proceed from the analytical structure of the expressions of the cost and time indicators under consideration, then there is no obvious conflict between them. The above does not contradict the concept of agents' utility [12], which is key in the welfare theory, if we approach this concept from the most general positions. As for the heterogeneity of these indicators, this circumstance allows us to take into account the interests of a different nature in relation to the agents under consideration. Along with directly economic and organizational issues, attention can also be paid to resource conservation, ensuring the rhythm of transportation, environmental friendliness. 


\subsection{Characteristics of the researched transportation process}

For the software implementation of the optimization algorithms developed in the paper, we turn to the analytical calculation system Maxima (Free Ware).

The corresponding computational procedures were performed for a specific transport and logistics project, in which it is assumed that the grain intended for transportation is located at the loading stations: Kamenskaya, Tselina, Beloglinskaya and Izobilnaya. Port stations are considered as unloading station: Zarechnaya, Azov, Taganrog and Yeisk (related to small ports), as well as Tuapse and Taman' stations (related to deep-water ports).

We proceed from the numerical data given in Table 1 . The time characteristics of the traffic flow are found taking into account its schedule speed.

Table 1. The traffic flow characteristics.

\begin{tabular}{|l|c|c|c|c|c|c|c|c|}
\hline \multirow{4}{*}{$\begin{array}{c}\text { Port } \\
\text { stations }\end{array}$} & \multicolumn{10}{|c|}{$\begin{array}{c}\boldsymbol{t}, \\
\text { days }\end{array}$} & $\begin{array}{c}\boldsymbol{c}, \\
\text { thousand } \\
\text { rubles }\end{array}$ & $\begin{array}{c}\boldsymbol{t}, \\
\text { days }\end{array}$ & $\begin{array}{c}\boldsymbol{c}, \\
\text { thousand } \\
\text { rubles }\end{array}$ & $\begin{array}{c}\boldsymbol{t}, \\
\text { days }\end{array}$ & $\begin{array}{c}\boldsymbol{c}, \\
\text { thousand } \\
\text { rubles }\end{array}$ & $\begin{array}{c}\boldsymbol{t}, \\
\text { days }\end{array}$ & $\begin{array}{c}\boldsymbol{c}, \\
\text { thousand } \\
\text { rubles }\end{array}$ \\
\hline Zarechnaya & 0,59 & 1021,14 & 0,44 & 938,46 & 0,77 & 1143,24 & 1,06 & 1332,72 \\
\hline Azov & 0,66 & 1064,34 & 0,51 & 980,58 & 0,84 & 1183,5 & 1,13 & 1391,22 \\
\hline Taganrog & 1,07 & 1183,5 & 0,92 & 1064,34 & 0,99 & 1272,84 & 1,29 & 1448,88 \\
\hline Yeisk & 0,82 & 1332,72 & 0,68 & 1222,92 & 0,78 & 1448,88 & 1,07 & 1623,84 \\
\hline Tuapse & 1,72 & 1877,52 & 1,43 & 1569,36 & 1,34 & 1332,72 & 1,25 & 1391,22 \\
\hline Taman' & 1,88 & 1877,52 & 1,47 & 1691,10 & 1,28 & 1448,88 & 1,38 & 1513,86 \\
\hline
\end{tabular}

\subsection{Preliminary results}

We will make explanations regarding the algorithm for solving the optimization problem considered in the paper, which can be set in one or another framework of the research of the transportation process. If we use mathematical classification, then the multicriteria problem of integer programming is solved. With an egalitarian approach in developing the appropriate algorithm, we rely on one of the basic rules in the welfare theory. This is the unanimity principle, for the implementation of which it is natural to turn to the concept of a Pareto optimal solution of a multicriterial problem. Thus, as a result of optimizing the transportation process, a balance of the agent interests in question is achieved.

With regard to the specifics of the state of the transport and logistics infrastructure in the railway network part considered in the paper, we will take into account the following circumstances. First, let's pay attention to the low capacity of railway approaches to the port stations Zarechnaya, Azov, Taganrog and Yeisk. At the same time, the absence of storage of sufficiently large capacity at these stations is no less important. Thus, there are very strict objective reasons for a very regulated and time-dosed use of the relevant transport infrastructure. Another important circumstance is specific (and external to transport) in nature. Namely, the railway network parts located in the direction of the port stations of Tuapse and Taman' are adjacent to the resort area (which, as is known, is located along the entire Black Sea coast of the Caucasus).

Let us proceed to the presentation of the results of preliminary researches. We start with the issues of optimizing the process of freight transportation with consideration of time indicators:

$$
\mathrm{T}_{1}=\sum_{\mathrm{j}=1}^{4} \tau^{(\mathrm{j})}, \quad \mathrm{T}_{2}=\sum_{\mathrm{j}=5}^{6} \tau^{(\mathrm{j})} \quad \text { and } \quad \mathrm{T} .
$$

It follows from expressions (3) and (4) that indicators (5) are related by equality: 


$$
\mathrm{T}_{1}+\mathrm{T}_{2}=\mathrm{T}
$$

In accordance with what has been said at the beginning of the subsection, we will optimize the transportation process with two time indicators $T_{1}$ and $T_{2}$ within the framework of the egalitarian approach. It should be noted that these indicators express the agent interests related to small and deep-water ports, respectively.

To each transportation plan $\left(x_{i j}\right) \in D$ we assign a vector $\left\{T_{1}, T_{2}\right\}$, called the utility vector. Let's call such a transportation plan $\left(x_{i j}^{*}\right) \in D$ optimal with the utility vector $\left\{T_{1}{ }^{*}, T_{2}{ }^{*}\right\}$, for which there is no transportation plan $\left(x_{i j}\right) \in D$ such that the coordinates of its utility vector $\left\{T_{1}, T_{2}\right\}$ satisfy the condition.

$$
\left(T_{1}<T_{1}^{*} \& T_{2} \leq T_{2}^{*}\right) \vee\left(T_{1} \leq T_{1}^{*} \& T_{2}<T_{2}^{*}\right)
$$

It follows from the expression of the logical connection (6) that in the process of optimizing transportation plans, the minimization of the values of the two indicators under consideration is carried out in an equal manner.

We present the results of performing computational procedures. First, let's consider the situation when there are 2 forwarder routes with grain at each of the four loading stations. With respect to the set $D$, we will make the following natural additional assumption. At least one forwarder route must be sent to the unloading stations belonging to small ports, as well as to the unloading stations belonging to deep-water ports. Table 2 shows 6 transportation plans out of 15 plans obtained by the Maxima program as "steps" in the "optimization ladder" as the improvement of feasible plans occurred according to the logical connection (6). From the optimal transportation plan contained in the last row of the table 2, it can be seen how uneven the forwarder routes distribution turns out to be at the unloading stations in the port. At the same time, not a single forwarder route gets to the stations of Azov, Taganrog and Yeisk.

\begin{tabular}{|c|c|c|c|c|c|c|c|c|c|c|}
\hline \multirow{2}{*}{ № } & \multirow[b]{2}{*}{ Transportation plans } & \multicolumn{6}{|c|}{$\begin{array}{c}\text { Number of routes } \\
\text { arriving } \\
\text { at port stations }\end{array}$} & \multirow[b]{2}{*}{$\mathbf{T}_{1}$} & \multirow[b]{2}{*}{$\mathbf{T}_{2}$} & \multirow[b]{2}{*}{$\mathbf{T}$} \\
\hline & & 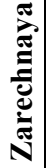 & $\frac{3}{8}$ & 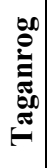 & $\frac{\pi}{\frac{\pi}{2}}$ & 岕 & E్ & & & \\
\hline 1 & $0,0,0,0,0,2,0,0,0,0,0,2,0,0,0,0,0,2,0,0,0,1,0,1$ & 0 & 0 & 0 & 1 & 0 & 7 & 1,07 & 10,64 & 11,71 \\
\hline$\ldots$ & $\ldots$ & $\ldots$ & $\ldots$ & $\ldots$ & $\ldots$ & $\ldots$ & $\ldots$ & $\ldots$ & $\ldots$ & $\ldots$ \\
\hline 5 & $0,0,0,0,0,2,0,0,0,0,0,2,1,0,0,0,0,1,0,0,0,0,2,0$ & 1 & 0 & 0 & 0 & 2 & 5 & 0,77 & 10,48 & 11,25 \\
\hline$\ldots$ & $\ldots$ & $\ldots$ & $\ldots$ & $\ldots$ & $\ldots$ & $\ldots$ & $\ldots$ & $\ldots$ & $\ldots$ & $\ldots$ \\
\hline 10 & $0,0,0,0,0,2,0,1,0,0,1,0,0,0,0,0,0,2,0,0,0,0,2,0$ & 0 & 1 & 0 & 0 & 3 & 4 & 0,51 & 10,25 & 10,76 \\
\hline 11 & $0,0,0,0,0,2,1,0,0,0,1,0,0,0,0,0,0,2,0,0,0,0,2,0$ & 1 & 0 & 0 & 0 & 3 & 4 & 0,44 & 10,25 & 10,69 \\
\hline$\ldots$ & $\ldots$ & $\ldots$ & $\ldots$ & $\ldots$ & $\ldots$ & $\ldots$ & $\ldots$ & $\ldots$ & $\ldots$ & $\ldots$ \\
\hline 15 & $0,0,0,0,2,0,1,0,0,0,1,0,0,0,0,0,0,2,0,0,0,0,2,0$ & 1 & 0 & 0 & 0 & 5 & 2 & 0,44 & 9,93 & 10,37 \\
\hline
\end{tabular}

Table 2. Forwarder routes distribution by stations and values of indicators.

Let us move on to optimizing the transportation process, which is carried out on the basis of utilitarian approach. Namely, we present the results of solving the corresponding optimization problem with consideration of only one time indicator $T$. The interested agents here can be the owner of the infrastructure, the carrier, the operator company and, of course, the agent "green logistics". 
Table 3 shows 5 transportation plans out of 188 plans, which correspond to the iterations carried out in the process of minimizing the objective function $T$. The values of the indicators $T_{1}$ and $T_{2}$ obtained in this case change very chaotically.

Table 3. Forwarder routes distribution by stations and values of indicators.

\begin{tabular}{|c|c|c|c|c|c|c|c|c|c|c|}
\hline \multirow[b]{2}{*}{ № } & \multirow[b]{2}{*}{ Transportation plans } & \multicolumn{6}{|c|}{$\begin{array}{c}\text { Number of routes } \\
\text { arriving } \\
\text { at port stations }\end{array}$} & \multirow[b]{2}{*}{$T_{1}$} & \multirow[b]{2}{*}{$T_{2}$} & \multirow[b]{2}{*}{$T$} \\
\hline & & 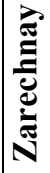 & ᄅ & 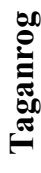 & $\frac{\sqrt{\sigma}}{2}$ & 总 & 气ే & & & \\
\hline 1 & $0,0,0,0,0,2,0,0,0,0,0,2,0,0,0,0,0,2,0,0,0,1,0,1$ & 0 & 0 & 0 & 1 & 0 & 7 & 1,07 & 10,64 & 11,71 \\
\hline 2 & $0,0,0,0,0,2,0,0,0,0,0,2,0,0,0,0,0,2,0,0,0,1,1,0$ & 0 & 0 & 0 & 1 & 1 & 6 & 1,07 & 10,51 & 11,58 \\
\hline 3 & $0,0,0,0,0,2,0,0,0,0,0,2,0,0,0,0,0,2,0,0,0,2,0,0$ & 0 & 0 & 0 & 2 & 0 & 6 & 2,14 & 9,26 & 11,40 \\
\hline$\ldots$ & $\ldots$ & $\ldots$ & $\ldots$ & $\ldots$ & $\ldots$ & $\ldots$ & $\ldots$ & $\ldots$ & $\ldots$ & $\ldots$ \\
\hline 187 & $2,0,0,0,0,0,2,0,0,0,0,0,1,0,0,1,0,0,1,0,0,0,1,0$ & 6 & 0 & 0 & 1 & 1 & 0 & 4,67 & 1,25 & 5,92 \\
\hline 188 & $2,0,0,0,0,0,2,0,0,0,0,0,2,0,0,0,0,0,1,0,0,0,1,0$ & 7 & 0 & 0 & 0 & 1 & 0 & 4,66 & 1,25 & 5,91 \\
\hline
\end{tabular}

The optimal transportation plan (see the last row of Table 3) is radically different from the one obtained earlier on the basis of an egalitarian approach to the optimization process. However, the port stations of Azov, Taganrog and Yeisk are also deprived of forwarder routes to their address.

\section{Results}

We introduce a number of additional restrictions in the optimization problem under consideration.

It's explained by the specifics of the ongoing research. It's means multimodality of transportation, as well as the desire to take into account the interests of such an agent as "green logistics". At first, let us pay attention to the fact that the ports of Taganrog and Yeisk (located on the coast of the Taganrog Bay of the Azov Sea), as well as the ports of Zarechnaya and Azov (located in the lower reaches of the Don) can enter vessel with a deadweight of 7 thousand tons.

We will assume that each such vessel is practically filled with two forwarder routes, consisting on average of 50 wagons with a carrying capacity of 64 tons each. Therefore, it seems rational to limit the forwarder routes number sent to the address of each of the corresponding port stations, could only be even.

\subsection{Optimization with a cost indicator}

Along with the time indicators of the transportation process, we will involve the cost indicator (2) in the ongoing research. Note that the basic rule in the welfare theory [12] in the utilitarian approach is expressed by the desire to maximize the sum of individual benefits of agents.

Combining the principles of egalitarian and utilitarian approaches, we will further consider the "combined" time indicator $T=T_{1}+T_{2}$. 
For each transportation plan $\left(x_{i j}\right) \in D$ we assign a vector $\{T, c\}$, called the utility vector. Let's call an optimal transportation plan $\left(x_{i j}^{*}\right) \in D$ with a utility vector $\left\{T^{*}, c^{*}\right\}$, for which there is no transportation plan $\left(x_{i j}\right) \in D$ such that the coordinates of its utility vector $\{T, c\}$ satisfy the condition.

$$
\left(T<T^{*} \& c \leq c^{*}\right) \vee\left(T \leq T^{*} \& c<c^{*}\right),
$$

It can be seen from the expression of the logical connection (7) that in the optimizing transportation plan process there is no loss of utility expressed by indicators $T$ и $c$.

Let us present the results of computational procedures performed in a situation when at each of the four loading stations there are 3 forwarder routes with grain.

Table 4 shows 5 plans out of 70 transportation plans, which are "steps" in the "optimization ladder" leading to one of the optimal transportations plans according to Pareto.

Table 4. Forwarder routes distribution by stations and values of indicators.

\begin{tabular}{|c|c|c|c|c|c|c|c|c|c|}
\hline \multirow[b]{2}{*}{ № } & \multirow[b]{2}{*}{ Transportation plans } & \multicolumn{6}{|c|}{$\begin{array}{c}\text { Number of routes } \\
\text { arriving } \\
\text { at port stations }\end{array}$} & \multirow[b]{2}{*}{$\mathbf{T}$} & \multirow[b]{2}{*}{$c$} \\
\hline & & 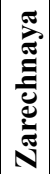 & 20 & 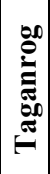 & $\frac{\pi}{20}$ & 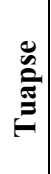 & & & \\
\hline 1 & $0,0,0,0,0,3,0,0,0,0,0,3,0,0,0,0,0,3,0,0,0,2,0,1$ & 0 & 0 & 0 & 2 & 0 & 10 & 17,41 & 19814,04 \\
\hline$\ldots$ & $\ldots$ & $\ldots$ & $\ldots$ & $\ldots$ & $\ldots$ & $\ldots$ & $\ldots$ & $\ldots$ & $\ldots$ \\
\hline 3 & $0,0,0,0,0,3,0,0,0,0,0,3,0,0,0,0,0,3,2,0,0,0,1,0$ & 2 & 0 & 0 & 0 & 1 & 9 & 17,26 & 19109,16 \\
\hline 4 & $0,0,0,0,0,3,0,0,0,0,0,3,0,0,0,2,0,1,2,0,0,0,1,0$ & 2 & 0 & 0 & 2 & 1 & 7 & 16,26 & 19109,16 \\
\hline$\ldots$ & $\ldots$ & $\ldots$ & $\ldots$ & $\ldots$ & $\ldots$ & $\ldots$ & $\ldots$ & $\ldots$ & $\ldots$ \\
\hline 69 & $2,1,0,0,0,0,1,2,0,0,0,0,2,1,0,0,0,0,1,0,0,0,2,0$ & 6 & 4 & 0 & 0 & 2 & 0 & 9,24 & 13591,38 \\
\hline 70 & $2,1,0,0,0,0,2,1,0,0,0,0,1,2,0,0,0,0,1,0,0,0,2,0$ & 6 & 4 & 0 & 0 & 2 & 0 & 9,24 & 13589,52 \\
\hline
\end{tabular}

We see that optimal transportation plan (in the last line of the table 4) is not balanced in terms of the forwarder routes number directed to small ports, as well as all ports considered.

Namely, all the forwarder routes were distributed between the three port stations, and to the Zarechnaya station half of all forwarder routes formed at the four unloading stations under consideration.

\subsection{Interests of the agent "green logistics"}

Let us return to the additional constraints in the optimization problem and take into account the fact that the port stations Zarechnaya and Taganrog are located within the two largest cities of the Rostov region boundaries. For these stations, the issues of environmental safety associated with grain dust emissions into the atmosphere during grain unloading / reloading are especially relevant. Based on the foregoing, we introduce a restriction so that the number of forwarder routes directed to the address of each of the Zarechnaya and Taganrog stations does not exceed two. 
Table 5 shows the computational procedures results (performed in accordance with the algorithm specified in subsection 3.1) obtained at the beginning and end of the freight transportation optimization process.

Table 5. Forwarder routes distribution by stations and values of indicators.

\begin{tabular}{|c|c|c|c|c|c|c|c|c|c|}
\hline \multirow{2}{*}{ № } & \multirow[b]{2}{*}{ Transportation plans } & \multicolumn{6}{|c|}{$\begin{array}{c}\text { Number of routes } \\
\text { arriving } \\
\text { at port stations }\end{array}$} & \multirow[b]{2}{*}{$\mathbf{T}$} & \multirow[b]{2}{*}{ c } \\
\hline & & 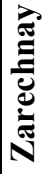 & $\underset{8}{\mathbf{3}}$ & 赵 & $\begin{array}{l}\frac{\pi}{0} \\
\frac{0}{d}\end{array}$ & 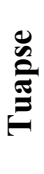 & ڤ్ & & \\
\hline 1 & $0,0,0,0,0,3,0,0,0,0,0,3,0,0,0,0,0,3,0,0,0,2,0,1$ & 0 & 0 & 0 & 2 & 0 & 10 & 17,41 & 19814,04 \\
\hline 2 & $0,0,0,0,0,3,0,0,0,0,0,3,0,0,0,0,0,3,0,0,0,2,1,0$ & 0 & 0 & 0 & 2 & 1 & 9 & 17,28 & 19691,40 \\
\hline$\ldots$ & $\ldots$ & $\ldots$ & $\ldots$ & $\ldots$ & $\ldots$ & $\ldots$ & $\ldots$ & $\ldots$ & $\ldots$ \\
\hline 64 & $0,2,0,1,0,0,1,2,0,0,0,0,0,2,0,1,0,0,1,0,0,0,2,0$ & 2 & 6 & 0 & 2 & 2 & 0 & 9,62 & 14292,06 \\
\hline 65 & $0,2,0,1,0,0,1,2,0,0,0,0,1,2,0,0,0,0,0,0,0,1,2,0$ & 2 & 6 & 0 & 2 & 2 & 0 & 9,62 & 14277,54 \\
\hline 66 & $1,2,0,0,0,0,1,2,0,0,0,0,0,2,0,1,0,0,0,0,0,1,2,0$ & 2 & 6 & 0 & 2 & 2 & 0 & 9,40 & 14271,60 \\
\hline
\end{tabular}

The values of indicators $T=9,40$ (day) and $c=14271,60$ (thousand rubles) of the optimal transportation plan (which obtained taking into account the above the agent "green logistics" additional interest) slightly exceed those obtained in the previous case (see Table 4). At the same time, the forwarder routes distribution by loading stations and port stations turns out to be more balanced.

\section{Discussion}

The multi-criteria model of freight transportation process at the loop allows for the optimization of this process within the framework of a set of indicators, the value of which is of interest to the agents under consideration. The results of the conducted mathematical experiments allow, in particular, to draw a general conclusion about the expediency of using egalitarian and utilitarian approaches, depending on the specific goals that are set in the transportation process research. The model is universal for land transport.

The following remark gives an idea of the number of calculations performed in the process of solving the problems under consideration. According to the formulas known from combinatorial analysis, in a situation where at each of the four loading stations there are 2 forwarder routes with grain, the set $D$ of all feasible transportation plans $\left(x_{i j}\right)$ satisfying equalities (1) consists of $\left(n^{m}\right)^{2}=\left(6^{4}\right)^{2}=6^{8}=1679616$ plans. Accordingly, in a situation where there are 3 forwarder routes at each of the loading stations, the number of all feasible transportation plans increases to $6^{12}=2176782336$.

\section{Conclusion}

With comprehensive research of the transportation process optimization, the synthesis of general methodological ideas turns out to be very productive and has practical applications. 
This research develops an approach to the organization of multimodal freight transportation on the near-port part of the railway loop, which is based on two concepts in the welfare theory. These concepts are considered in relation to the participants of the transportation process (referred to as agents) in terms of time and cost indicators of this process.

Egalitarianism proceeds from the unanimity principle, which is implemented by referring to the concept of a Pareto optimal solution to a multi-criteria optimization problem. Utilitarianism is expressed by the desire to maximize the sum of the individual utility of all the agents under consideration and does not imply their equality. The combination of egalitarian and utilitarian concepts makes it possible to significantly expand and diversify the set of feasible transportation plans, which may be preferable for agents in terms of the indicators under consideration.

Specialized software tools provide opportunities for creating mathematically sound and logistically versatile models of the freight transportation market. Mathematical experiment plays a significant role in the developed modeling methodology. This highly effective tool allows versatile and purposeful manipulation of the transportation process indicators and the restrictions imposed on transportation plans. At the same time, the specifics of multimodal transportation and the interests of agents are taken into account, the most important of which is a "green logistics".

\section{References}

1. N. El-Berishy, I. Rügge, B. Scholz-Reiter, IFAC Proceedings Volumes, 46, 24 (2013)

2. R. Stekeloruma, I. Laguirb, S. Guptac, S. Kumard, Int. J. of Production Economics, 235 (2021)

3. Y. Wang, S. Penga, X. Zhoub, M. Mahmoudic, L. Zhen, Transportation Research Part E: Logistics and Transportation Review, 143 (2020)

4. Y. Agyabeng-Mensah, E. Afum, E. Ahenkorah, J. of Cleaner Production, 258 (2020)

5. L. Y. Alexandrova, O. F. Kireeva, E. V. Krasilnikova, A. Y. Munshi, S. V. Timofeev, Frontier Information Technology and Systems Research in Cooperative Economics, 316 (2021)

6. E. Twrdya, M. Zannea, Transportation Research Procedia, 45 (2020)

7. R. A. Foroutan, J. Rezaeian, I. Mahdavi, Applied Soft Computing, 94 (2020)

8. M. Lacknera, P. Skowronb, Artificial Intelligence, 288 (2020)

9. M.-K. Kim, D. Park, M. Kim, J. Heo, S. Park, H. Chong, Atmosphere, 12, 70 (2021)

10. The Green Transformation of Deutsche Bahn (Deutsche Bahn AG, 2020)

11. Key Developments \& Implications (Sustainable Logistics, 2020)

12. H. Moulin, Axioms of Cooperative Decision Making, Econometric Society Monographs (Cambridge, Cambridge University Press, New York, 1989)

13. V. Bogachev, A. Kravets, T. Bogachev, ICIEAM 2021 (2021)

14. A. Kravets, V. Bogachev, I. Egorova, T. Bogachev, Transportation Research Procedia, $54(2021)$ 